\title{
EM TEMPOS DE CORONAVÍRUS: HOME OFFICE E O TRABALHO FEMININO
}

\author{
Coronavirus times: home office and the female work \\ En tiempos de Coronavirus: home office y el trabajo femenino
}

Thiele da Costa Müller Castro'

Priscila Pavan Detoni ${ }^{2}$

Carla Garcia Bottega ${ }^{3}$

Jaqueline Titton $^{4}$

\begin{abstract}
Resumo
As mulheres geralmente são mais afetadas em momentos de epidemias e pandemias, inclusive no meio acadêmico, como este que estamos vivenciando com a COVID 19. A metodologia desse artigo está baseada na autoetnografia das autoras, todas ligadas à academia por serem professoras, pesquisadoras e estão estudando. As questões orientadoras foram as mobilizações iniciais diante da pandemia e as estratégias utilizadas para a continuidade ou não de uma rotina, especialmente da conciliação do trabalho em home office, vida doméstica e pessoal em tempos de cuidados para a proteção da vida. Destaca-se a condição de privilégios que possibilita interseccionar o trabalho feminino, com a branquitude e o ofício docente. As narrativas mostraram, principalmente, a sobrecarga da mulher na sobreposição do trabalho doméstico e profissional, bem como a fragilização dos limites entre os espaços públicos e privado trazidas pelo trabalho via tecnologias digitais.
\end{abstract}

Palavras-chave: Pandemia; Trabalho feminino; Saúde Mental; Narrativa; Home office.

\begin{abstract}
' Psicóloga, Mestra e Doutoranda em Psicologia Social e Institucional pela Universidade Federal do Rio Grande do Sul - UFRGS. Integrante do NEITS - Núcleo de Estudos em Imagem, Trabalho e Subjetividade. Pesquisadora na área de saúde mental, trabalho e tecnologias. Email: thielemuller@msn.com Cidade: Porto Alegre/RS.

2 Psicóloga, Mestre e Doutora em Psicologia Social e Institucional pela Universidade Federal do Rio Grande do Sul (UFRGS - 2016); Colaboradora do Núcleo de Pesquisa em Relações de Gênero e Sexualidade (Nupsex/UFRGS) e na Pesquisa "A Covid-19 no Brasil: análise e resposta aos impactos sociais da pandemia entre profissionais da saúde e população em isolamento"; Docente na Universidade Federal da Fronteira Sul (UFFS) Campus Passo Fundo/RS. E-mail: ppavandetoni@gmail.com Cidade: Passo Fundo.

3 Psicóloga, Doutora e Mestre em Psicologia Social e Institucional, Docente em Saúde Coletiva pela Universidade Estadual do Rio Grande do Sul - UERGS. E-mail: carla-bottega@uergs.edu.br Cidade: Porto Alegre.

4 Professora do Programa de Pós-Graduação em Psicologia Social e Institucional da Universidade Federal do Rio Grande do Sul. Porto Alegre - RS. Coordenadora do NEITS - Núcleo de Estudos em Imagem, Trabalho e Subjetividade. Pesquisadora na área de trabalho, saúde e subjetividade com foco nos estudos que utilizam a produção de imagens como estratégia metodológica. Email: jatittoni@gmail.com Cidade: Porto Alegre.
\end{abstract}


Em tempos de coronavírus: home office e o trabalho feminino | Thiele da Costa Müller Castro | Priscila Pavan Detoni | Carla Garcia Bottega \& Jaqueline Titton

Women usually get more affected during times of epidemics and pandemics, including within academia, such as the one we are living with COVID 19. The methodology of this article was based in the autoethnography of the authors, all connected to academia for being professors, researchers, and for being students. The guiding questions were the initial mobilizations of the pandemic and the strategies used to maintain or not a routine, especially one that conciliates home office work, domestic and personal life during a time of caring for protecting lives. It is highlighted the privileges that allow us to intersect women's work, whiteness, and professorship. The narratives show, especially, the overbearing of women on the intertwining of domestic and professional work, as well as the fragility of the boundaries between public and private spaces brought by the work via digital technologies.

Keywords: Pandemic; Female Work; Mental health; Narrative; Home office.

\section{Resumen}

Las mujeres generalmente son más afectadas en momentos de epidemias y pandemias, incluso en la academia, como este tiempo en que estamos viviendo com la COVID 19. La metodología utilizada para este artículo se basó en la autoetnografía de las autoras, todas conectadas a la academia pues profesoras, investigadoras y están estudiando. Las cuestiones orientadoras fueron las movilizaciones iniciales de la pandemia y las estrategias usadas para la continuidad o no de una rutina, especialmente las de conciliación del trabajo home office, vida doméstica y personal en tiempos de cuidados para la protección de la vida. Destacamos la condición de privilegio que nos habilita interseccionar eltrabajofemenino, con la blanquitud y el trabajo de profesora. Las narrativas mostraron, principalmente, la sobrecarga de las mujeres en la superposición del trabajo doméstico y profesional, así como la fragilidad de los límites entre los espacios público y privado que trajo el trabajo vía tecnologías digitales.

Palabras-clave: Pandemia; Trabajo Femenino; Salud mental; Narrativa; Home office.

\section{Introdução - Por que escrever um diário?}

Se me fosse dado um dia, outra oportunidade, eu nem olhava o relógio. Seguiria sempre em frente e iria jogando pelo caminho a casca dourada e inútil das horas... (Mário Quintana)

Quando começamos as trocas sobre nosso cotidiano em meio ao isolamento físico ${ }^{5}$ ocasionado pela pandemia, descobrimos que algumas de nós já estávamos escrevendo diários, ou fazendo pequenas escritas. E a cada encontro virtual, as questões de ser mulher em meio a todos os

\footnotetext{
5 Neste texto, utilizamos o conceito de isolamento fisico, colocado por Brum (2020) "Quem criou esse conceito - "isolamento social" - estava com falha de raciocínio. O que temos que fazer e muitos estão fazendo é "isolamento físico. O que está acontecendo hoje é exatamente o contrário de isolamento social. Fazia muito tempo que as pessoas, no mundo inteiro, não socializavam tanto. No Brasil, o grande momento de socialização tem sido o panelaço de "Fora Bolsonaro!" nas janelas."
} 
Em tempos de coronavírus: home office e o trabalho feminino | Thiele da Costa Müller Castro | Priscila Pavan Detoni | Carla Garcia Bottega \& Jaqueline Titton

acontecimentos tinham um peso diferente. O trabalho, o cuidar dos filhos, o cuidar da família, os cuidados com a casa, eram inúmeros os temas que nos remetiam ao ser mulher, e nos davam pistas do nosso modo de estar nestes tempos. Percebemos que todas as discussões nos levavam às tecnologias, ao trabalho em home office ${ }^{6}$, às reuniões virtuais, as festas e os encontros com a família e amigos, que também só se faziam possíveis através de aplicativos. A proposta de todas escreverem diários durante uma semana logo iniciado o primeiro mês de pandemia, e compartilhar com o coletivo veio como mais uma tecnologia que seria usada em tempos de crise.

Essa narrativa se encontra em uma liberdade localizada, de escrita acadêmica, impulsionadas por uma necessidade de relatar a si mesmas em um periodo de isolamento físico e de assombros de uma pandemia. Ocupamos um lugar de privilégio, de não estar somente lutando pela própria sobrevivência, diferente daquelas que estão dentro de outras narrativas, como dos números de mortas, desempregadas e para as quais falta acesso à saúde e a educação.

Contudo, ocupamos um lugar de mulheres, cisgêneras, brancas, professoras e/ou pesquisadoras em diferentes percursos, de início e final de carreira, através de aulas virtualizadas nas universidades federais e estaduais. Mesmo que possamos entender isto redimensionado a partir desse momento, temos privilégios. Diferente da situação da maioria das mulheres brasileiras em que a casa ainda representa um espaço de trabalho não remunerado, com sobrecarga, somando as violências domésticas (MOREIRA et al., 2020).

Por isso, escrever um diário, escrever notas, escrever na agenda. Escrever para marcar o tempo presente, e o que passa, que precisa ser marcado para não esquecermos e para lembrarmos constantemente as singularidades e as diferenças. Os dias nessa pandemia são estranhos,

\footnotetext{
6 Utilizamos o termo home office para retratar a transição de muitos trabalhadores para o seu lar, em um movimento de montagem de espaços fisicos para atender as demandas de trabalho dentro de suas casas. Diferentemente do teletrabalho, que já está previsto em lei, precisa cumprir alguns requisitos contratuais e pressupõe uma plataforma digital da instituição, que liga o trabalhador a ela.
} 
Em tempos de coronavírus: home office e o trabalho feminino | Thiele da Costa Müller Castro | Priscila Pavan Detoni | Carla Garcia Bottega \& Jaqueline Titton

perdemos a noção do que fizemos, pois não saímos para fazer as atividades cotidianas, trabalhar, comprar, passear, se exercitar... O que fiz hoje? Começa a ficar dificil de lembrar e ao mesmo tempo difícil de escrever, é o tensionamento de escrever o que se vive, enquanto está se vivendo.

Nossa escrita pode e deve expressar o que buscamos incessantemente como práticas cotidianas: a convivência respeitosa com ideias e propostas diferentes que se constituam em construtos coletivos que superem os processos de individualização, promovendo grupalidades. Assim como nos afetamos, queremos que outras sejam afetadas com relações mais solidárias e afetivas, baseadas numa prática ético-política.

Inicialmente muitas informações das mais diversas fontes, televisão, e-mail, WhatsApp, todas parecem muito atordoadas (anestesiadas e agitadas). Ao mesmo tempo em que temos a preocupação com a pandemia, o (des) governo, principalmente em nivel federal, nos deixa ainda mais inseguras. A pandemia avança, mas não avançam na mesma velocidade as medidas protetivas $\mathrm{e}$ as estratégias da saúde pública. Infelizmente, vivenciamos uma governamentalidade necropolítica (MBEMBE, 2016), em que muitas vidas são descartadas, principalmente de mulheres negras, que são, geralmente, a população mais atingida no histórico de epidemias (PIMENTA, 2020). Não há tempo para pensar, tudo é rápido, o tempo dos dias parece escorrer pelas mãos, como Cronos (BULFINCH, 2000) que destrói tudo que cria, e aí habita uma de nossas questões, sobre manter ou não a rotina.

Vivenciar esses acontecimentos faz emergir muitas questões, como repensar o trabalho doméstico, a relação com os outros(as) moradores(as) da casa, com os alunos e alunas, com as tecnologias, com a sobrecarga de trabalho, com os acontecimentos políticos e com as incertezas que se apresentam em diferentes esferas. E para que escrever? Além de marcar esse tempo do cotidiano, para poder reler depois tudo que aconteceu. Para nos sentirmos vivas, para compartilharmos nossas ansiedades e angústias, além 
Em tempos de coronavírus: home office e o trabalho feminino | Thiele da Costa Müller Castro | Priscila Pavan Detoni | Carla Garcia Bottega \& Jaqueline Titton

do espaço da psicoterapia individual, e para compartilhar com outras que vivem situações semelhantes para não se sentirem tão sós. Acreditamos que esta seja uma forma de nos mantermos solidárias, comprometidas com um coletivo e atuantes em uma composição possivel. Neste exercício nos inspiramos nas narrativas e na autoetnografia para contar e resistir nas experiências vividas. Assim, traremos um relato das várias si-mesmas, a partir das condições de possibilidades e estruturais em uma narrativa singular, mas nunca completa, pelas limitações que tornam irrecuperáveis toda a complexidade para o entendimento de nós mesmas ${ }^{7}$.

\section{Caminho metodológico}

Este escrito apresenta a produção de conhecimento a partir de narrativas autoetnográficas sobre trabalho feminino e home office em tempos de isolamento físico devido a pandemia do Covid-19. É um esforço de redação atravessado pela construção do próprio objeto de estudo, ou seja, em um constante processo de invenção (GRANADA, 2019). Buscamos enfatizar a problematização das narrativas produzidas sob dois aspectos: a narrativa das situações vivenciadas e o lugar ocupado pelas pesquisadoras como mulheres, professoras e pesquisadoras.

Almeida et al., (2020) usam a autoetnografia, para entender o aprendizado como uma ferramenta pedagógica exploratória do cotidiano em suas linhas subjetivadoras, da mesma maneira que traçamos uma narrativa do desenho de quatro diários escritos durante o isolamento físico na pandemia. A etnografia convencional faz uma inserção no meio, trabalha com o olhar de estranhamento, aproxima-se das discussões teóricas sobre o campo, que visa a descrição e o entendimento integrativo de fenômenos socioculturais presentes em grupos ou comunidades particulares, com dimensão ao mesmo tempo metodológica e ética (SOUZA, 2015). Contudo, reconhecemos que esta proposta não se trata de uma etnografia

\footnotetext{
7 Neste texto, optamos por usar o gênero feminino predominantemente na escrita, na medida em que as autoras são mulheres e pretendem principalmente, mas não só, compartilhar a narrativa com outras mulheres neste período de pandemia.
} 
Em tempos de coronavírus: home office e o trabalho feminino | Thiele da Costa Müller Castro | Priscila Pavan Detoni | Carla Garcia Bottega \& Jaqueline Titton

convencional ainda que se inspire nos seus pressupostos, pois ela parte das experiências particulares e de escritas reflexivas na forma de diários, ressaltando as narrativas que quem pesquisa faz de sua experiência. Para Santos (2017) a etnografia consiste em construir uma narrativa sobre um grupo de pertença a partir de si mesmo, que possui forte caráter reflexivo e subjetivo, podendo ter elementos autobiográficos. Encontramos estudos autoetnográficos no campo das ciências sociais, como o de Santos (2017), nas artes dramáticas (SANTOS e BIANCALANA, 2017) ou na saúde (ALMEIDA et al., 2020) mostrando a amplitude de sua expressão.

Onocko-Campos e Furtado $(2008,2013)$ organizaram revisão de diferentes autores que se ocuparam do tema das narrativas. Neste estudo, relacionam o entendimento das várias correntes teóricas da narrativa como:

\begin{abstract}
categoria de mediação: [...] para a crítica literária de Ricoeur, como mediação entre discurso e ação: para as correntes historiográficas, como mediação entre conhecimento e estrutura; para as correntes da comunicação, como mediação entre indivíduo e sociedade; para a psicanálise de Kristeva, como mediação entre memória e ação politica (ONOCKO-CAMPOS e FURTADO, 2008, p. 1095).
\end{abstract}

A narrativa pode ser considerada uma forma de linguagem em que os eventos se apresentam em uma sequência, com um início, um desenvolvimento e um final, ou uma possível finalização a critério dos participantes; mas em uma perspectiva de constructo coletivo, foge à proposta mais descritiva e cronologicamente organizada. Geralmente existe um narrador ou narradores e um ouvinte ou ouvintes para a direção da narrativa, mas a narrativa não é uma relação passiva, ela acontece de forma conjunta sendo influenciada pelas diferentes perspectivas dos participantes na junção das subjetividades.

Nesse sentido, estão presentes nessa construção tanto sujeitos individuais quanto coletivos, constituindo um "dispositivo poroso de comunicação" na construção de "novos olhares narrativos" (ONOCKOCAMPOS e FURTADO, 2008, p. 1095). Na medida em que há sempre um viés relacional, é nessa relação intersubjetiva que alguns aspectos do narrado terão maior ou menor destaque na versão. A narrativa tem como 
Em tempos de coronavírus: home office e o trabalho feminino | Thiele da Costa Müller Castro | Priscila Pavan Detoni | Carla Garcia Bottega \& Jaqueline Titton

caráter dar maior evidência, no relatar, ao que as pessoas sentem e o que os demais envolvidos na construção narrativa sentem em relação ao que está sendo narrado, visto que uma narrativa, ainda que descritiva, se produz sobre bases subjetivas e escolhas marcadas moral e eticamente. As narrativas constituem-se assim como uma "forma de descrever experiências vividas" neste caráter de "função mediadora" (ONOCKO-CAMPOS et al., 2013, p. 2848). Proporciona engajamento e possibilidade aos participantes de interpretação, não tendo uma direção única ou a priori.

Para Butler (2015), o exercício do relato de si nos constitui enquanto sujeitos, sujeitos esses que podem ou não narrar sobre si, mas, mesmo quando não nos narramos, estamos dentro de uma narrativa e de uma cena de interpelação, seja até mesmo pela narrativa negada ou modificada. Portanto, a capacidade narrativa pode ser uma precondição para a responsabilidade das nossas ações, possuindo um conteúdo ético e reflexivo importante. Para a autora, a narrativa de si emerge de um conjunto de condições de possibilidade que a tornam possível e a conformam de certo modo, com certa cadência e conteúdo. Narrar a si mesmo, deste modo, está relacionado a um sistema de razão que estabelece um si mesmo relevante e passivel de reflexão sobre si mesmo e suas condições de emergência.

Se tento dar um relato de mim mesma, e se tento me fazer reconhecivel e compreensivel, devo começar com um relato narrativo da minha vida. Mas essa narrativa será desorientada pelo que não é meu, ou não é só meu. E, até certo ponto, terei que fazer substituível para me fazer reconhecivel. A autoridade narrativa do "eu" deve dar lugar à perspectiva e à temporalidade de um conjunto de normas que contesta a singularidade da minha história (BUTLER, 2015, p. 52).

Foucault (2007) examinou as condições hermenêuticas, que faz o si mesmo ser objeto de reflexão nas formações pré modernas de sujeito. O autor destacou os sujeitos como efeitos dos discursos nos escritos, ou no conjunto de códigos que revelam sua constituição e estabelecem uma criação de si como crítica mais ampla. Para tanto, essa prática de estilização de si mesmo em relação às normas e a conduta moral não é uma questão de conformar-se às prescrições estabelecidas, nem tampouco interiorizar as interdições, mas assumir a consciência de si, em que a ação moral é 
Em tempos de coronavírus: home office e o trabalho feminino | Thiele da Costa Müller Castro | Priscila Pavan Detoni | Carla Garcia Bottega \& Jaqueline Titton

indissociável das práticas e usos de si. Portanto, a moral pode ser recriada nas relações do sujeito, do mesmo modo que a narração de si mesmo.

Filtrado pelas lentes da linguagem, da classe social, do gênero, da raça e da região que ocupamos, é impossivel separar o pessoal, do teórico, do politico, por isso, vamos escrever, para buscar produzir um nós, no lugar de um eu. E o faremos através da narrativa autoetnográfica, que se faz em ato, que intersecciona experiências vividas e institucionalizadas, que pretende questionar suas implicações na autoria e na transformação subjetiva, testando limites e conceitos (ALMEIDA et al., 2020). A autoetnografia, aqui implicada nas reflexões trazidas pela problematização das narrativas de si e de seus desdobramentos éticos e políticos.

Trata-se de um tempo intenso, em que buscamos narrar a experiência vivida e a ação presente conjugadas pela memória, ao mesmo tempo em que buscamos com esta marca da narrativa, a projeção de algo futuro, como expectativa do porvir incerto. Apresentamos narrativas dos mesmos acontecimentos com pontos de vista variados, de uma aparente repetição daquilo que é experimentado na vida cotidiana; ao mesmo tempo em que explicamos a experimentação, buscamos a compreensão do que estamos narrando, para nós mesmas e para as demais ouvintes/leitoras/participantes. Propõe-se tensionar as linhas que ligam narradora-narradoras, num exercício constante que nos tira desse sentir solitário para um sentir compartilhado-solidário.

As autoras escreveram seus diários durante a primeira semana do mês de abril de 2020, ou seja, na terceira semana de distanciamento social devido a pandemia, no Brasil; estas escritas foram compartilhadas em um drive. A partir do compartilhamento, os escritos foram lidos por todas que começaram a articular narrativas, antes individuais, para uma escrita coletiva, entrelaçada. O que inicialmente poderia ter sido escrito por apenas uma das autoras passa a se fundir, já não fazendo mais sentido a autoria, mas sim aquilo que a narrativa expressa, um discurso coletivo. Assim, o que 
Em tempos de coronavírus: home office e o trabalho feminino | Thiele da Costa Müller Castro | Priscila Pavan Detoni | Carla Garcia Bottega \& Jaqueline Titton

passará a ser compartilhado a partir daqui é uma composição deste grupo, mas também de outras narradoras, que mesmo não estando na autoria expressa deste texto, também estão presentes agregando e trazendo novas composições, pelas conexões de redes estabelecidas pelas autoras com as mulheres externas a este grupo, suas famílias, relações de amizade e de trabalho que foram construindo cotidianamente a trama da narrativa. A leitora encontrará as falas recortadas dos diários em escritas entre aspas no decorrer do texto.

\section{Narrativas de Mulheres Professoras e/ou Pesquisadoras}

A pandemia nos coloca no (des)conforto do espaço doméstico, umas sozinhas, outras com filhos, filhas e companheiros. Aos poucos vão se juntando a nós as plantas, flores, gatos e cachorros, que convidamos para compor conosco estes novos tempos. Com o passar do tempo, aparentemente, as coisas vão se acomodando. Como o ditado popular: "é no andar da carruagem que as melancias se ajeitam". Parecemos melancias na carruagem tentando nos "ajeitar" em nossas casas e apartamentos. Temos o trabalho doméstico e docente, ambos marcados pela feminização, associados ao cuidado e ao privado, e a desigualdade de gênero que marca o estabelecimento de forma sociocultural de diferenças entre os polos binários feminino e masculino (BUTLER, 2013).

Tudo se mistura, vida intima e pública. Se antes essa mistura era constatada e sentida, com a pandemia se trata de uma total invasão, na medida em que o trabalho invadiu o que ainda havia de intimo. Trabalhar em home office, exigiu que montássemos estruturas de trabalho remoto que necessariamente não tínhamos, além de nos expor e deixar disponíveis o tempo todo. Somos invadidas por câmeras e contatos constantes, onde não existe mais um tempo dentro e um tempo fora. Críticas que faziamos ao teletrabalho e trabalho remoto em nossos estudos e pesquisas, agora fazem parte da nossa rotina. Andamos pela casa com o celular na mão, uma ferramenta indispensável, que Deleuze (1992, p. 224) nomina, de forma 
Em tempos de coronavírus: home office e o trabalho feminino | Thiele da Costa Müller Castro | Priscila Pavan Detoni | Carla Garcia Bottega \& Jaqueline Titton

muito perspicaz, de "coleira eletrônica". A experiência de subjetividade e corporalidade dessas novas formas de comunicação modifica a relação entre indivíduo e coletivo, e potencializa o capitalismo e seus meios de exploração, como o utilitarismo dos equipamentos, internet, luz custeadas pelo próprio sujeito (SEGATA, 2020).

Mantermo-nos conectadas 24 horas por dia parece garantir a sensação de não afastamento do que acontece na rua. Esse momento faz relembrar Cecília Coimbra (2001) que, ao falar das "classes perigosas", diz que a rua é o lugar do perigo e a segurança está no lar. Com certeza esta é a produção da família nuclear burguesa, do lar como abrigo e como espaço de segurança, sendo a rua, espaço do perigo, do vício e do crime. Agora isso é uma realidade na medida em que a rua, e sair à rua, é ainda mais perigoso, o que se cruza e se retroalimenta em relação ao contágio do vírus. Só nos sentimos protegidas dentro de nossas casas e tudo que vem de fora parece ameaçador, ao mesmo tempo em que tudo que queremos, é estar fora. Nossas práticas e experiências são marcadas por construções coletivas, para o coletivo que agora é ameaçador, mas também ameaçado. Voltamo-nos para o cuidado individual, familiar, tendo a certeza de que esse cuidado de si é o cuidado com o outro. É uma dança, de ir e vir, e a tentativa de entender a distância necessária, e a presença importante e militante em tempos de crise. Habitamos o paradoxo.

"Existem dois trabalhos que nunca acabam": o doméstico e o acadêmico. Mas mudamos o cenário, não nos deslocamos mais de casa para a universidade, e sim levamos a universidade para dentro de nossas casas. Essa mudança brusca e repentina não nos oportunizou a elaboração do que estava acontecendo. Simplesmente vimos nossa residência, espaço íntimo, tornando-se palco de nosso trabalho, gerando mais sobrecarga.

Os oficios de donas de casa e professoras ocupam o lugar de feminização (no âmbito quantitativo de maior número de mulheres nestes trabalhos) e de feminilização (pelas características femininas atribuídas 
Em tempos de coronavírus: home office e o trabalho feminino | Thiele da Costa Müller Castro | Priscila Pavan Detoni | Carla Garcia Bottega \& Jaqueline Titton

nestas atividades de trabalho) (YANNOULAS, 2011), acionados pelas tecnologias de gênero que o capitalismo convencionou como trabalhos privados e de cuidado para as mulheres, uma vez que o capitalismo garantiu uma melhor mobilidade social para todos e não para todas (ZANELLO, 2018). A feminilização do trabalho doméstico expande-se dos limites familiares, para inscrever-se nas atividades profissionais, interligando trabalho e raça, na medida em que quase a totalidade das pessoas que realizam trabalho doméstico no Brasil são mulheres e a grande maioria são mulheres negras. A racialização do trabalho doméstico, enfatizada por Davis (2016), já nos anos oitenta do século passado e que faz referência ao período de escravidão norte-americano, complexifica o pensamento feminista e coloca em questão as mulheres que, para terem uma vida profissional fora de casa, delegam o trabalho doméstico a outra mulher, muitas vezes, negra. Toda pandemia é generificada, racializada e tem classe social, por isso, Pimenta (2020) afirma que neste momento no Brasil a pandemia se localiza na mulher preta e periférica e, por vezes, deficiente.

$\mathrm{Na}$ pandemia, a sobrecarga das mulheres profissionais que realizam home office, na maioria das vezes, está ligada à ausência de outra mulher, que faz o trabalho doméstico na casa, o que faz parte dos efeitos da branquitude. Pimenta (2020) reforça que em pandemia/endemia/epidemia existem marcas de raça, gênero e classe social, ou seja, um fenômeno nada democrático, que atinge mais as mulheres - como a pandemia do novo coronavirus no Brasil. Assim, a feminização do trabalho aborda não somente a quantidade de trabalho, mas a qualidade associada àquele trabalho, que faz o dispositivo materno atuar sob todas as mulheres, independentes de serem ou não mães, mas se ocuparem "voluntariamente" ou por "instinto" com o cuidado de crianças, de pessoas idosas ou doentes próximas (ZANELLO, 2018). Esse dispositivo materno, se encontra presente em muitos dos nossos escritos nos diários, quando nos vemos gerenciando demandas familiares presenciais e por telefone, e o cuidado com pessoas mais velhas 
Em tempos de coronavírus: home office e o trabalho feminino | Thiele da Costa Müller Castro | Priscila Pavan Detoni | Carla Garcia Bottega \& Jaqueline Titton

que estão isoladas, seja revezando um tempo na sua casa ou auxiliando outra mulher nessa tarefa.

O trabalho doméstico, na divisão de tarefas, historicamente foi algo atribuído às mulheres. Neste momento de home office, esta situação se torna ainda mais evidente. Os discursos vigentes interpelam muito mais às mulheres do que aos homens sobre os cuidados domésticos e maternos. Estudos demonstram que o trabalho feminino doméstico é pouco reconhecido e obrigatório para muitas mulheres; naturalizando-se a duplicidade ou triplicidade da jornada em ser mãe e trabalhadora. Geralmente, nas epidemias as mulheres são responsáveis pelo cuidado com doentes e com a gestão dos recursos domésticos, o que as sobrecarregam física e psicologicamente (PIMENTA, 2020).

Já estamos cansadas das listas de coisas para fazer no tempo ocioso - filmes, séries e livros. "Que tempo ocioso é esse? Para quem tem o desafio de ir ao mercado, esterilizar todas as compras, fazer café, almoço e janta, limpar a casa. Ah, não podemos esquecer de fazer o bolo para o lanche da família." Responder demandas que não param, habitar um espaço e um corpo que precisam ser onipresentes e onipotentes. Precisamos ainda ler relatórios, revisar artigos, preparar aulas para alunos e alunas que dizem que não estão com vontade de ter aula pela angústia que sentem nesse momento, mas querem um espaço de acolhimento e escuta que a aula pode proporcionar, e para se sentir parte de algo maior.

As alunas mães trazem para a aula virtualizada as suas crianças, as explicações são interrompidas por choros, pedidos, entregas e até latidos de cachorros. A vida acontece, dos dois lados da tela, pois deste lado não é diferente. Apesar de os pais também estarem em casa é o nome da mãe que é invocado pelas crianças, e na maioria das vezes são as mulheres que renunciam a seus trabalhos para atender as demandas domésticas. "Tenho a sensação de que meu trabalho é menos importante." A mensagem que fica é que já existe uma regra estabelecida que é sempre a mulher quem vai abrir 
Em tempos de coronavírus: home office e o trabalho feminino | Thiele da Costa Müller Castro | Priscila Pavan Detoni | Carla Garcia Bottega \& Jaqueline Titton

mão de seus compromissos em prol da família e do lar. Ser mulher em diferentes sociedades implica no aprendizado da administração e gestão do cuidado desde meninas (PIMENTA, 2020). Por isso, na articulação entre casa e trabalho, podemos analisar que o trabalho reprodutivo, de cuidado com os/as filhos/as e com as tarefas domésticas, reproduzem carga física e mental acentuada para as mulheres, com o agravante de ser compreendido não como trabalho, mas como parte do cuidado e do carinho materno (MOREIRA et al., 2020). E ainda reforçado pelo dispositivo materno, que reitera essa naturalização de trabalho não remunerado no cuidado do lar (ZANELLO, 2018).

Ainda como parte do cuidado a escuta acolhedora para com os outros se faz constante, "Duas alunas, em contextos diferentes, escrevem contando que trancaram o curso de graduação, porque estão com os filhos pequenos em casa, sem escola, sem creche e não conseguem acompanhar as aulas, e outra ainda está desempregada, e se separou no meio da pandemia." Tentamos pensar saídas. O gênero precisa ser pensado sempre como uma categoria constitutiva, assim como o trabalho e o produto do capitalismo vigente - a divisão sexual do trabalho e da renda. Através da sororidade entre professoras e alunas buscamos desconstruir a instituição de que o feminino estaria ligado a fragilidade e submissão, mesmo que hoje sejamos um país de maioria mulheres, inclusive chefes de família e negras, somos ainda profundamente subjetivadas pelo sexismo atrelado ao machismo, ao patriarcado, e ao racismo. Por isso, precisamos resistir a uma política que desconsidera os marcadores sociais da diferença, nega a ciência e inclusive a letalidade do coronavirus.

"Entre muitas reuniões para ressignificar o papel da universidade neste momento, orientações, escritas e livros, não há bateria que aguente tantas horas, seja no celular ou no notebook." Começamos um embate com as tecnologias, que até outrora amigas, agora se mostram insistentes e presentes em demasiado. "Esse isolamento tem acabado com a privacidade que antes deixava o meu lar e as prateleiras bagunçadas". Como diz 
Em tempos de coronavírus: home office e o trabalho feminino | Thiele da Costa Müller Castro | Priscila Pavan Detoni | Carla Garcia Bottega \& Jaqueline Titton

Mansano (2009) no título de uma de suas obras "sorria, você está sendo controlado".

Enquanto sujeitas contemporâneas, altamente tecnológicas, já vínhamos inseridas em um contexto de super exposição em redes sociais, que são tratados como naturais, atuando como terreno fértil para o capitalismo. A cereja do bolo parece ter chegado com o avanço da pandemia e a urgência do recolhimento de quem pode fazer isolamento físico em suas casas, pois este movimento faz com que não mais seja mostrado apenas a performatividade da felicidade irreal, passando a mostrar a realidade de todas, através da lente do trabalho em home office. De acordo com Sibilia (2016), da intimidade à extimidade.

Utilizamos o termo home office para pontuar o deslocamento do trabalho para dentro de casa, da montagem de escritórios em quartos, salas ou cozinhas, lugar de onde iremos produzir, receber colegas, alunos, professores, mas também amigos e familiares. Trabalhando através de tecnologias entramos nas casas das pessoas, e também abrimos as janelas de nossas casas, janelas do computador e celular mostrando nossa vida privada como um espetáculo, que faz com que qualquer desavisado que passe atrás da gente seja capturado e transportado para dentro de uma reunião, sem nem mesmo conhecer o assunto.

Sibilia (2012) ilustra um paralelo entre a sociedade disciplinar e sociedade controle, e afirma,

$$
\begin{aligned}
& \text { fugir do controle em que estamos "enredados" e sobreviver à } \\
& \text { saturação por hiperconexão parece bem mais dificil, talvez por se } \\
& \text { tratar de nossa própria batalha e por nela estar em jogo nada menos } \\
& \text { que nossas vidas }(2012, \text { p. 199). }
\end{aligned}
$$

A autora nos traz o conceito de telepresença, e é assim que nos sentimos operando durante esse período de isolamento físico. Há um misto de solidão, saudade, perda e ao mesmo tempo o exagero de uma telepresença constante, de todos os tipos (SIBILIA, 2015). Telepresença para assuntos profissionais e também pessoais, gerando "saudades de estar junto, dar abraços. Parece que vou abrir a porta e sair a qualquer momento", 
Em tempos de coronavírus: home office e o trabalho feminino | Thiele da Costa Müller Castro | Priscila Pavan Detoni | Carla Garcia Bottega \& Jaqueline Titton

para que a presença não mais precise da tecnologia da tela. Sentimentos também apontados por Preciado (2020) sobre a vida após COVID-19, "Eu não tive medo de morrer. Eu tive medo de morrer sozinho".

Não temos soluções e nem previsão para o fim do afastamento do trabalho presencial, para o reencontro com sorrisos, abraços, afetos que fazem valer os engarrafamentos, o ônibus lotado, os quilômetros viajados, acordar mais cedo e chegar mais tarde em casa. "Deslocamentos que nos faziam chegar em casa e poder sentir o refúgio e não o escritório, a sala de aula, de reuniões, de contatos, de horizontes limitantes que invadem o espaço que antes era particular. Também não temos certeza de qual mundo encontraremos quando sairmos de nossas casas", Preciado (2020) relata: "Quando fui para a minha cama, o mundo era unido, coletivo, viscoso e sujo. Quando saí da cama, ele havia se tornado distante, individual, seco e higiênico."

Para Preciado (2020) a pandemia centralizou quase toda a produção no lar, inclusive reproduziu instituições tradicionais como escola e fábrica nesse local de controle biopolítico. Em que somos capturadas pelas lógicas capitalistas de produtividade e empreendedorismo, onde cada trabalhadora se responsabiliza por todos os gastos com o seu próprio trabalho, seja pela rede de internet, luz, equipamentos que precisam de manutenção e reposição para o home office.

"Refaço as aulas, reescrevo, desaprendo a ser eu na frente da câmera. Meus alunos desligam o microfone e a câmera para me assistir, assim não vejo os rostos, não sei se estão compreendendo, se estão entendendo ou não. Uma aula sem relação não é uma aula, uma aula sem essa troca, é a coisificação.” Entra a questão da solidão, mas também do reconhecimento e do olhar do outro para minha produção. Como saber se estou atingindo meus objetivos com esta turma? Lévy (1993, p. 7) já nos alertava que "novas maneiras de pensar e de conviver estão sendo elaboradas no mundo das telecomunicações e da informática”, começamos a sentir na pele essas novas maneiras como única alternativa de comunicação. Em pleno ano de 2020 
Em tempos de coronavírus: home office e o trabalho feminino | Thiele da Costa Müller Castro | Priscila Pavan Detoni | Carla Garcia Bottega \& Jaqueline Titton

não podemos dizer que as tecnologias que estamos usando são novas, mas o que se coloca em questão é a falta de liberdade de escolher outras formas de relação.

A relação com o tempo também se torna outra. Não há separação entre lugar e tempo de trabalhar e de descansar. Tudo vai se tecendo como se fosse a mesma coisa. Perdemos a noção das horas, da rotina, dos intervalos. "Ligamos o computador às $9 \mathrm{~h}$. Só conseguimos sair da frente dele depois das $13 \mathrm{~h}$, fazemos o almoço ouvindo os áudios no WhatsApp. Lavamos a louça escutando alguma live que ficou para trás, mas tem gravação. Logo após corremos de volta para o computador. Das 14:30 até as $22 \mathrm{~h}$, ficamos num entra e sai de reunião remota, fazemos combinações pelo telefone, atendemos as crianças, fazemos os temas, lembramos que precisamos organizar a logística das compras. Levantamos, sentamos, levantamos, sentamos. E trabalhamos até às $22 \mathrm{~h} . .$. quando nos damos conta que temos que parar. Jantar, fazer as crianças dormirem... e quando elas dormem... corremos terminar o trabalho que não tem fim."

Sibilia, quando discute sobre a inserção do relógio como marcador do tempo afirma:

É claro que tal esquadrinhamento do tempo não ocorreu sem violência: os organismos humanos tiveram que sofrer uma série de operações para se adaptar aos novos compassos, dando à luz outras formas de ser, de estar e de movimentar-se nas coordenadas espaçotemporais (2015, p. 22).

Essa relação com a tecnologia vai trazendo sintomas e vamos montando estratégias. "A tarde me sento na frente do computador para trabalhar, os olhos pesam, as costas doem. Penso que poderia já ser sábado. Mas tenho que vencer o que preciso fazer hoje, pois a cada dia a demanda de trabalho aumenta mais. Poderia não ter aumentado se a estratégia fosse paralisar, mas não foi. Foi produzir, se afetar, ajudar, se sensibilizar, pensar, sofrer e criar. A produção não no sentido capitalista, mas uma produção crítica." O trabalho pode tanto favorecer à doença quanto à saúde, não há neutralidade, sempre buscamos estratégias para nos defender 
Em tempos de coronavírus: home office e o trabalho feminino | Thiele da Costa Müller Castro | Priscila Pavan Detoni | Carla Garcia Bottega \& Jaqueline Titton

psiquicamente das adversidades provenientes das pressões dos modelos de gestão e da organização do trabalho (DEJOURS, 1999). Não existe divisão entre espaço de trabalho e espaço privado, principalmente quando remetemos às relações sociais, pois não é possível separar nossa vida em casa da vida no trabalho, mesmo que o trabalho docente sempre tivesse atividades de planejamento e avaliativas, antes e depois das aulas, fora do tempo das aulas. Psiquicamente estes ambientes se misturam, e tornam essa relação difícil de ser equacionada. Nesse momento, com tudo ocorrendo praticamente no mesmo ambiente, da casa, essa separação é impossivel.

Para nos protegermos, tanto das adversidades do trabalho, quanto de pensarmos sobre a pandemia, criamos estratégias de aceleração e sobrecarga e de anestesiamento e amortecimento, a fim de afastarmos o risco de contaminação e morte que corremos. Infelizmente, como estamos isoladas em casa, nosso ambiente atual de trabalho, as estratégias são, à princípio, de ordem individual, mas buscamos compartilhar com outras nossos sentimentos para não reagirmos sozinhas.

Perez et al., (2019), ao apresentarem alguns elementos do mundo do trabalho e saúde mental nas universidades, apontam que hoje se vive uma precarização do trabalho docente, com sujeição e uma amplificação do uso de plataformas para o ensino à distância, principalmente nas universidades privadas. Mas atualmente, com a pandemia, estes elementos vêm fazendo parte também das instituições públicas, pois há uma necessidade de enxugamento de custos, flexibilização de jornadas e horários, além da busca pelo alcance de mais alunos e alunas. No ambiente acadêmico, as mulheres são as mais afetadas na pandemia, principalmente as intelectuais negras, na medida em que ainda temos uma maior produção de artigos de homens brancos neste período (PIMENTA, 2020).

Esses tempos de varejo do ensino à distância poderão precarizar ainda mais as relações de trabalho docente. Será que vai mesmo aumentar o reconhecimento na área da educação, e da saúde, e o Sistema Único de Saúde (SUS)? E o trabalho das mulheres autônomas que contratariamos não 
Em tempos de coronavírus: home office e o trabalho feminino | Thiele da Costa Müller Castro | Priscila Pavan Detoni | Carla Garcia Bottega \& Jaqueline Titton

fosse esse momento, a faxineira, a manicure, a podóloga - cabe pagar por esses serviços que não serão cobertos pela distribuição de renda emergencial dos 600 reais destinados pelo governo? Pagamos nossas prestadoras de serviços, destacando nosso lugar de privilégios de ter a manutenção da renda, nesses momentos sentimos realizadas no trabalho, apesar das crescentes dificuldades e desvalorizações, mas somos marcadas, por duas gerações diferentes, duas de nós lutou pelo processo de democratização no seu percurso educacional e começo profissional, outras duas já conheceram uma constituição, o SUS e o Estatuto da Criança e do Adolescente (ECA) ainda crianças. Isso faz muita diferença nas estratégias de lidar com o presente.

Também é importante destacar o quanto a pandemia deixa evidente a importância de um sistema público de saúde, principalmente num país com tamanha desigualdade social, onde $70 \%$ da população depende exclusivamente do SUS. Ao mesmo tempo em que nunca se falou tanto no SUS, e que sem ele a nossa situação poderia ser muito pior, também a necessidade de uso massivo dos serviços de saúde ao mesmo tempo, explicita o subfinanciamento histórico da saúde e sua consequente precarização para dar conta desta necessidade. Os diários mostram "Na palestra virtualizada pela primeira vez escuto a maioria dos alunos defendendo o SUS e não atacando, entendendo a sua função de controle de doenças. São estudantes que já realizaram atendimentos no SUS, como estágio, e ouviram de gestores que fazer grupos é não estar atendendo, por que são medidos pelo número de consultas. Então, os alunos passam a se entender como trabalhadores também e não somente como elite."

É evidente que a falta de prioridade da saúde é política, explicitada pelos ataques ao desmonte do sistema. Paim (2018) e Campos (2018), ao levantarem desafios para o SUS, apontam que o sistema foi implantado, mas ainda não consolidado e que os poderes executivo, legislativo e judiciário, não tem assegurado as condições objetivas para a sustentabilidade 
Em tempos de coronavírus: home office e o trabalho feminino | Thiele da Costa Müller Castro | Priscila Pavan Detoni | Carla Garcia Bottega \& Jaqueline Titton

econômica e científico-tecnológica do SUS, somado a isso o "subfinanciamento crônico" do sistema fica constitucionalizado, cristalizando as dificuldades acumuladas. Ainda temos as convicções políticas, a negação versus o pânico da pandemia, o medo da morte. Isso tudo desgasta ao ponto que tenhamos noites mal dormidas. Percebemos, através da leitura dos diários, que todas recorremos à live do Ricardo Antunes, na ânsia de encontrar respostas, discussões possiveis, e revitalizamos um marxismo que já não existe mais, e de um capitalismo que captura até mesmo a pandemia, e quem consegue ter privilégios e lucros diante dela. Como se não nos bastasse a pandemia e seu isolamento físico, ainda convivemos com as incertezas diárias e uma forma de governar necropolítica. Um governo que não oficializa as orientações provenientes da Organização Mundial da Saúde (OMS) e outras instituições mundiais em defesa da manutenção da vida, que indicam medidas protetivas que poderiam preservar vidas.

Para Brum (2020), a pandemia expõe o "apartheid não oficial do Brasil", fica claro aqueles e aquelas que podem e os que não podem ser contaminados e contaminadas. Isso se explicita na medida em que são negados os direitos de isolamento físico para parcela da população que necessita permanecer trabalhando, usando transporte público, além dos que vivem em casas sem saneamento, água e cômodos para acomodar a família. Muitas dessas pessoas continuam trabalhando para que os que estão em isolamento possam ter suas casas limpas, a comida feita, além de atenderem as necessidades essenciais dos que podem pagar. A desigualdade social está mais do que demonstrada, apesar do vírus não escolher a classe social, os mais expostos, morrerão mais.

Autores como Dejours (2004), Campos (2013; 2000), Passos (2013), apontam que os coletivos de produção organizados podem construir possibilidades democráticas de contraposição e resistência às adversidades vividas no cotidiano. Nesse sentido, o espaço de encontro, de grupo, é também de resistência e de força que, com sua produção, desestabiliza o instituído, fortalecendo seus participantes. Num processo de construção 
Em tempos de coronavírus: home office e o trabalho feminino | Thiele da Costa Müller Castro | Priscila Pavan Detoni | Carla Garcia Bottega \& Jaqueline Titton

constante, de produção e constituição de novas práticas, de emergência do novo, saindo do particular, pessoal e privado para o público e coletivo. Nesses encontros, produtores de novas subjetividades, construímos narrativas recheadas de aspectos sociais, históricos e políticos, de vivências e experiências compartilhadas.

\section{Linhas de fuga, captura ou saídas?}

O que pode uma pandemia? Afinal não existe um fora, estamos todas dentro dessa pandemia, não há para onde fugir, se não para dentro de si e com os seus. Durante esta vivência intensa, produzir não foi fácil, é difícil escrever sobre o que se vive enquanto se vive. Nossa composição se deu por encontros, afetos, escritas terapêuticas, acolhimentos e potência de vida. Uma pandemia devasta vidas, leva quem amamos, nos coloca no iminente risco constante, nos perturba. Mas também nos traz a certeza de que as coisas não podem mais ficar como estavam. Assim, como Fassin (2018) destaca que um dos papéis ocupados pela antropologia contemporânea e das produções advindas dela, deveriam se esforçar para "repolitizar o mundo", ou seja, deslocar o olhar das formas superficiais da política, no sentido de responder aos questionamentos elaborados por diferentes sujeitos. Por isso, fizemos o exercício de olhar nós mesmas.

Assim, percebemos que manter ou não a rotina não faz mais questão. O bombardeio de avisos que recebemos para mantermos a rotina se fez falacioso, pois a rotina se estabeleceu a partir de outros parâmetros, como ausência de trânsito e a não necessidade de deslocamento, mas também pela constante demanda de acolhimento em crise.

$\mathrm{O}$ nó que se apresenta para nós, mulheres, trabalhadoras, é reforçado e elevado à décima potência: como conciliar nosso trabalho, a vida pessoal e os afazeres domésticos em tempos de pandemia? Não encontramos respostas, mesmo ocupando um lugar marcado por muitos privilégios, como renda, profissão e classe social. 
Em tempos de coronavírus: home office e o trabalho feminino | Thiele da Costa Müller Castro | Priscila Pavan Detoni | Carla Garcia Bottega \& Jaqueline Titton

Quando estará marcado um fim? Ou o fim dessa narrativa?

Desejos e anseios, diante do tempo, da tecnologia, do ser mulher e do habitar este mundo. Han (2017), quando se refere a sociedade da aceleração, afirma que o movimento, em seu excesso, perde a causa de si mesmo. O mundo está passando por um ritual ou cerimônia de reconstruir as relações, para isso precisamos de tempo. Todos os processos e acontecimentos narrativos não se dão em aceleração, eles não podem ser operacionalizados. A possibilidade de ocorrerem experiências transformadoras, de tornar-se outra, é tão mais importante que a simples vivência, pois esta deixa intacto aquilo que já existe, e se assim for de nada valeram os acontecimentos. E nisso tudo como ficam as mulheres super aceleradas e sobrecarregadas? Percebemos que não temos como finalizar com respostas. Já viviamos uma diminuição dos encontros e uma precarização da vida pública, mas desejamos que essa imposição, que também passa por uma escolha, de ficar longe dos que amamos para protegê-los, nos traga uma ressignificação do que são laços, afetos e encontros. Que nosso senso de vida coletiva e de corresponsabilização se aflore, que nossas ações se tornem potentes de afetos pulsantes. Que não nos preocupemos em voltar ao que era antes o mais breve possivel, mas que sejamos inundadas de criatividade para inventarmos novas formas de ser e habitar este mundo tão precário e injusto. Que possamos perceber os direitos de todos e todas, que consigamos compor com as diferenças.

\section{Referências:}

ALMEIDA, Diego Eugênio Roquette Godoy et al. Autoetnografia como estratégia decolonizadora de ensino sobre o cotidiano em Terapia Ocupacional. Interface (Botucatu), Botucatu, v. 24, e190122, 2020. Disponivel em http://www.scielo.br/scielo.php?script=sci_arttext\&pid=S141432832020000 100505\&lng=pt\&nrm=iso. Acesso em 09 maio 2020.Epub 16-Mar2020. https://doi.org/10.1590/interface.190122.

BRUM, Eliane. COVID-19. Três perguntas a Eliane Brum. Entrevista concedida a Sérgio Costa. Revista Renascença. 24 de abril 2020. Disponivel em: https://rr.sapo.pt/2020/04/24/mundo/a-pandemia-expos- 
Em tempos de coronavírus: home office e o trabalho feminino | Thiele da Costa Müller Castro | Priscila Pavan Detoni | Carla Garcia Bottega \& Jaqueline Titton

o-apartheid-nao-oficial-do-brasil-em-toda-a-sua brutalidade/especial/190424/. Acesso em 02 de maio de 2020.

BULFINCH, Thomas. O livro de ouro da mitologia: histórias de deuses e heróis. Rio de janeiro: Ediouro, 2000.

BUTLER, Judith. Problemas de gênero: feminismo e subversão de identidade. 6 ed. Rio de Janeiro: Civilização Brasileira, 2013.

BUTLER, Judith. Relatar a si mesmo: crítica da violência ética. Tradução: Rogério Bettoni, 1ed. Belo Horizonte: Autêntica Editora, 2015.

CAMPOS, G. W. S. Saúde paidéia. São Paulo: Hucitec, 2013.

CAMPOS, G. W. S. Um método para análise e co-gestão de coletivos: a construção do sujeito, a produção de valor de uso e a democracia em instituições: o método da roda. São Paulo: Hucitec, 2000.

CAMPOS, Gastão Wagner de Sousa. SUS: o que e como fazer? Ciênc. saúde coletiva, Rio de Janeiro, v. 23, n. 6, p. 1707-1714, junho de 2018. Disponivel em http:/ /www.scielo.br/scielo.php?script=sci arttext\&pid=S1413$81232018000601707 \& \operatorname{lng}=$ en\&nrm=iso . Acesso em 21 de outubro de 2019. http://dx.doi.org/10.1590/1413-81232018236.05582018.

COIMBRA, Cecília Maria Bouças. Operação Rio: o mito das classes perigosas. Rio de Janeiro/Niterói: Oficina do Autor/Intertexto, 2001.

DAVIS, Angela. Mulheres, Raça e Classe. São Paulo: Boitempo, 2016.

DEJOURS, C. Addendum: da psicopatologia à psicodinâmica do trabalho. Em S. Lancman \& L. I. Sznelwar (Orgs.), Christophe Dejours - Da psicopatologia à psicodinâmica do trabalho (pp. 47-104). Rio de Janeiro: Fiocruz, Brasília: Paralelo 15, 2004.

DEJOURS, C. Conferências Brasileiras: identidade, reconhecimento e transgressão no trabalho. São Paulo: Fundap: EAESP/FGV, 1999.

DELEUZE, G. Post-scriptum sobre as sociedades de controle (1990). In: Conversações. São Paulo: Editora 34, p. 219-226, 1992.

FASSIN, Didier. Por una repolitización del mundo. Las vidas descartables como desafio del siglo XXI. Buenos Aires: Siglo XXI Editora Iberoamericana, 2018.

FOUCAULT, Michel. História da Sexualidade, 2: O Uso dos Prazeres. 5.ed. Rio de Janeiro, Edições Graal, 2007. 
Em tempos de coronavírus: home office e o trabalho feminino | Thiele da Costa Müller Castro | Priscila Pavan Detoni | Carla Garcia Bottega \& Jaqueline Titton

GRANADA FERREIRA, D. Práticas em movimento: a pesquisa de campo no caso da capoeira fora do Brasil. Sociedade e Cultura, v. 22, n. 1, 23 maio 2019.

HAN, Byung-Chul. Sociedade da transparência. Petrópolis, RJ: Vozes, 2017.

LEVY, Pierre. As tecnologias da inteligência: o futuro do pensamento na era da informática. Rio de Janeiro: Ed. 34, 1993.

MANSANO, Sonia R. V. Sorria, você está sendo controlado. Resistência e poder na sociedade de controle. São Paulo: Summus, 2009.

MBEMBE, A. Necropolitica. Arte e Ensaios. Rio de Janeiro, n. 32, pp. 123151, dezembro de 2016. Disponível em: https://revistas.ufrj.br/index.php/ae/article/view/8993. Acesso em: 06 set. 2020.

MOREIRA, Lisandra Espindula et al. Mulheres em tempos de pandemia: um ensaio teórico-político sobre a casa e a guerra. Psicol. Soc., Belo Horizonte, v. 32, e020014, 2020. Disponivel em: http://www.scielo.br/scielo.php?script=sci_arttext\&pid=S010271822020000 100413\&lng=en\&nrm=iso. Acesso em: 06 set. 2020. Epub set. 04, 2020. https://doi.org/10.1590/1807-0310/2020v32240246.

ONOCKO-CAMPOS et al. Narrativas no estudo das práticas em saúde mental: contribuições das perspectivas de Paul Ricoeur, Walter Benjamim e da antropologia médica. Ciência e Saúde Coletiva. Rio de Janeiro, v. 18, n. 10 , p. 2.847-2.857, 2013.

ONOCKO-CAMPOS, R.; FURTADO, J. Narrativas: utilização na pesquisa qualitativa em saúde. Revista de Saúde Pública. São Paulo, v. 42, n. 6, p. 1.090-1.096, 2008.

ONOCKO CAMPOS, R.T.; FURTADO, J.P. Narrativas: apontando alguns caminhos para sua utilização na pesquisa qualitativa em saúde. In: ONOCKO CAMPOS, R.T.; FURTADO, J. P.; PASSOS, E.; BENEVIDES, R. (Org.) Pesquisa Avaliativa em Saúde Mental: desenho participativo e efeitos da narratividade. 2 ed. São Paulo: Hucitec Editora, 2013.

PAIM, Jairnilson Silva. Sistema Único de Saúde (SUS) por 30 anos. Ciênc. saúde coletiva, Rio de Janeiro, v. 23, n. 6, p. 1723-1728, junho de 2018. Disponivel em http://www.scielo.br/scielo.php?script=sci_arttext\&pid=S141381232018000 601723\&lng=en\&nrm=iso. Acesso em 21 de out. de 2019. http:/ /dx.doi.org/10.1590/1413-81232018236.09172018. 
Em tempos de coronavírus: home office e o trabalho feminino | Thiele da Costa Müller Castro | Priscila Pavan Detoni | Carla Garcia Bottega \& Jaqueline Titton

PASSOS, E. A construção da clínica do comum e as áreas profissionais. In: CAPOZZOLO, A. A.; CASETTO, S. J. \& HENZ, A. O. (Orgs.). Clínica comum: itinerários de uma formação em saúde (pp. 213-228). São Paulo: Hucitec, 2013.

PEREZ, K. V.; RODRIGUES, C. M. L.; BRUN, L. G. Saúde mental no contexto universitário: desafios e práticas. Trabalho (En)Cena, v. 4, p. 357-365, 2019.

PIMENTA, Denise. Pandemia é coisa de mulher: breve ensaio sobre o enfrentamento de uma doença a partir das vozes e silenciamentos femininos dentro das casas, hospitais e na produção acadêmica. Tessitura. Revista de Antropologia e Arqueologia. V. 8, N. 1, 2020. Disponível em: https://periodicos.ufpel.edu.br/ojs2/index.php/tessituras/article/view/189 00. Acesso em: 30 set. 2020

PRECIADO, Paul B. A Conspiração Dos Perdedores. Select- Terra Notícias, 2020 Disponível em: https://www.select.art.br/a-conspiracao-dosperdedores/ Acesso em 05 de maio de 2020.

QUINTANA, Mário. Poesia Completa. Rio de Janeiro: Nova Aguilar. 2005.

SANTOS, S. M. A. O método da autoetnografia na pesquisa sociológica: atores, perspectivas e desafios. Plural, [S. 1.], v. 24, n. 1, p. 214-241, 2017. DOI: 10.11606/issn.2176-8099.pcso.2017.113972. Disponivel em: http://www.revistas.usp.br/plural/article/view/113972. Acesso em: 16 out. 2020.

SANTOS, Camila M.; BIANCALANA, Gisela R. Autoetnografia: um caminho metodológico para a pesquisa em artes performativas. Revista Aspas, Vol. 7, n. $\quad 2, \quad$ p. $\quad 83-93$, file:///C:/Users/jatit/Downloads/137980Texto\%20do\%20artigo-292113-2-10-20180511.pdf. 2017.

SEGATA, Jean. A colonização digital do isolamento. Cadernos de Campo (USP), v. 29, p. 163-171, 2020.

SIBILIA, Paula. Redes ou paredes: A escola em tempos de dispersão. Rio de Janeiro: Contraponto, 2012.

SIBILIA, Paula. O homem pós-orgânico: A alquimia dos corpos e das almas à luz das tecnologias digitais. $2^{\mathrm{a}}$ ed. Rio de Janeiro: Contraponto, 2015.

SIBILIA, Paula. O show do eu. $2^{\text {a }}$ ed. Rio de Janeiro: Contraponto, 2016.

SOUZA, Mauricio Rodrigues de. Psicologia Social e Etnografia: Histórico e Possibilidades de Contato. Psicol. cienc. prof., Brasília, v. 35, n. 2, p. 389405, junho de 2015. Disponivel em < 
Em tempos de coronavírus: home office e o trabalho feminino | Thiele da Costa Müller Castro | Priscila Pavan Detoni | Carla Garcia Bottega \& Jaqueline Titton

http://www.scielo.br/scielo.php?script=sci_arttext\&pid=S141498932015000 200389\&lng=en\&nrm=iso $>$. Acesso em 14 de maio de 2020. http://dx.doi.org/10.1590/1982-370301742013.

YANNOULAS, Silvia C. "Feminização ou feminilização? Apontamentos em torno de uma categoria". Temporalis, Brasília, v. 11, n. 22, p. 271-292, jul./dez. 2011.

ZANELLO, V. Saúde Mental, Gênero e Dispositivos: Cultura e Processos de Subjetivação. 1. ed. Curitiba: Appris, v. 1. 303p, 2018. 